$\xi=-1$

\title{
Chitosan-Zinc Oxide Composite for Active Food Packaging Applications
}

\author{
S.R. Abdul Razak ${ }^{1}$ and H. Basri ${ }^{2 *}$ \\ ${ }^{1}$ Department of Technology and Natural Resources, ${ }^{2}$ Department of Physics \& Chemistry, \\ Faculty of Applied Sciences and Technology, \\ Universiti Tun Hussein Onn Malaysia, Pagoh Education Hub, Km 1 Jln Panchor, 84600 Muar, Johor, Malaysia \\ *Corresponding author E-mail: hatijah@uthm.edu.my
}

\begin{abstract}
Chitosan-zinc oxide $(\mathrm{C}-\mathrm{ZnO})$ films were prepared by a simple one pot procedure. In order to investigate the property of $\mathrm{C}$ - $\mathrm{ZnO}$ films, two composite films were prepared by varying the loading of $\mathrm{ZnO}$ and compared with pure chitosan film (C). The films were characterized by various techniques such as FTIR, DSC, tensile, contact angle and water vapour permeability. FTIR analysis showed changes in hydrogen bonds band at $3351 \mathrm{~cm}^{-1}$ compared to pure chitosan film. The incorporation of $\mathrm{ZnO}$ in chitosan films increased the contact angle by $30.5 \%$ in $\mathrm{C}-\mathrm{ZnO} 1.0$ film while water vapour transmission rate decreased by $7.8 \%$ compared to $\mathrm{C}$ film. From the tensile test, $\mathrm{C}$ $\mathrm{ZnO} 0.5$ and $\mathrm{C}-\mathrm{ZnO} 1.0$ films were found to be much superior by 1.5 times and 2.5 times respectively compared to bare chitosan film. Larger inhibition ring (by 47\%) was exhibited by C-ZnO1.0 as compared to C-ZnO0.5 when tested against S.aureus. From the results, it is displayed that the incorporation of zinc oxide to chitosan improve their properties which also shown the potential to become a candidate for food active packaging.
\end{abstract}

Keywords: Active Packaging, Antimicrobial, Chitosan, Contact Angle, Zinc Oxide

\section{Introduction}

A good packaging material can prevent and/or minimize food spoilage caused by microbial contamination. The functions of food packaging traditionally, are to preserve, extend shelf life and deliver the food products until consumption [1]. The right selection of material used in food packaging is crucial especially for active food packaging application in order to maintain product quality and freshness during distribution and storage. Active packaging emerges as a promising technology in response to consumer demand, towards mildly preserved, safe, and high-quality foods as it is designed to control the development of decay and disease caused by microorganisms for extending shelf life, maintaining food safety, reducing wastage and minimizing the risks for foodborne diseases [2].

Chitosan is a biopolymer extracted mainly from the crustacean shell, which is mostly thrown out as waste from the food processing industries [3]. Structurally, chitosan is a cationic polysaccharide with B-(1-4)-linked d-glucosamine (deacetylated unit) and $\mathrm{N}$-acetyl-d-glucosamine (acetylated unit) distributed randomly [4]. Chitosan has a great potential to be used as active material because of its antimicrobial activity, nontoxicity, and low permeability to oxygen [5]. However, the use of chitosan alone does not fulfill the criteria of an ideal packaging film because of high water vapour permeability which may promote bacterial growth and also it is not much effective against common bacterial strains that cause food spoilage [6]. Hence, it is always desirable to incorporated additive such as metal oxide in chitosan matrix to improve its limited mechanical and antimicrobial properties for better performance of chitosan film [7].
The ability of chitosan to accommodate new materials in its matrix is due to the presence of large

number of pendant groups like $-\mathrm{NH}_{2}$ and $-\mathrm{OH}$ [8]. Among the metal oxides, zinc oxide is one of the most widely applied materials in food and pharmacy fields due to its antimicrobial properties, high stability, non-toxicity, and good UV absorbance properties [9]. Additionally, it is generally recognized as safe (GRAS) from FDA (182.8991 code) [10].

The aim of the study was to synthesize chitosan-zinc oxide (C$\mathrm{ZnO}$ ) films by adopting a simple one pot procedure, which will contribute to the development of active food packaging applications. The physicochemical properties (FTIR, DSC, WVTR and contact angle), mechanical properties (elongation at break and tensile) and antimicrobial properties of the films were investigated.

\section{Material and Methods}

\subsection{Materials}

Low molecular weight chitosan was purchased from local supplier while acetic acid, ethanol and $\mathrm{ZnO}$ were purchased from Sigma Aldrich. Bacteria strain S. aureus (gram-positive, TISTR 1466) was cultured in the Food Microbiology Laboratory, Universiti Tun Hussein Onn Malaysia. All chemical used in this study were analytical grade.

\subsection{Preparation of Chitosan- $\mathrm{ZnO}$ film}

Chitosan-ZnO films were prepared according to Rahman et.al. [11]. Typically, $2.0 \mathrm{~g}$ of chitosan was dissolved in $100 \mathrm{ml} 2 \%$ 
$(\mathrm{v} / \mathrm{v})$ aqueous acetic acid for $24 \mathrm{~h}$ at room temperature. Then $\mathrm{ZnO}$ powder $(0.5$ or $1.0 \mathrm{~g})$ was added in the solution and sonicated again for $1 \mathrm{~h}$. The viscous mixture was casted and dried at room temperature. Glass plate with dried thin film was immersed into $0.2 \mathrm{~mol} \mathrm{~L}^{-1} \mathrm{NaOH}$ solution for wet separation. The film was kept in oven at $60{ }^{\circ} \mathrm{C}$ for $4 \mathrm{~h}$ before being washed with ethanol 3 times and dried.

\subsection{Fourier transform infrared (FTIR) spectroscopy}

The FTIR analysis was performed with a Nicolet iS5 FTIR spectrometer (Thermo Scientific, Madison, WI, USA). OMNIC TM spectra software v 9.3.32 software (Thermo Nicolet Corp., Madison, WI) was used to analyse the spectrum. Film was placed onto a diamond crystal and the analysis was performed within the spectral region of $500-4000 \mathrm{~cm}^{-1}$, with 32 scans recorded at $4 \mathrm{~cm}^{-1}$ resolution.

\subsection{Differential scanning calorimetry (DSC) analysis}

A Netzsch DSC 214 apparatus (Germany) equipped with an intracooler system was used for DSC measurements. After calibration with a high-purity indium standard, the calorimetric analysis was carried out under dry nitrogen flow $(60 \mathrm{~mL} / \mathrm{min})$ at heating rate 10 ${ }^{\circ} \mathrm{C} /$ min using closed standard aluminium pans containing $\sim(7-10)$ $\mathrm{mg}$ of sample.

\subsection{Tensile}

Mechanical properties of chitosan- $\mathrm{ZnO}$ films were determined using Instron Universal testing machine (Model-3345) based on Rahman et.al. [12]. The values of tensile strength (TS) and percentage at elongation $(\% \mathrm{E})$ were reported as the average of three replications.

\subsection{Contact angle}

The dynamic contact angle of distilled water drop on the chitosan$\mathrm{ZnO}$ composite films was measured with an OCA20 programmed and software Controlled Video-Based Contact Angle Meter (Data Physics Instruments GmbH, Filder-stadt, Germany)

\subsection{Water vapour transmission rate}

The water vapour transmission rate (WVTR) of the films was determined according to ASTM E96-95 method [12]. The test film sealed on the top of cup contain distilled water and the distance between water level and film should be $20 \mathrm{~mm}$. It was placed in desiccator at $25^{\circ} \mathrm{C}$ and $0 \%$ relative humidity $(0 \mathrm{~Pa}$ water vapour pressure) with silica gel. The amount of water vapour transferred through the films was measured as the mass loss of the test cup at a time interval of $1 \mathrm{~h}$. The slope of weight loss versus time was obtained via linear regression. The measurement (WVTR) of the films was determined as follows:

$W V T R=$ graph slope of weight loss versus time

\subsection{Antimicrobial properties}

The antimicrobial activity of films were evaluated against $S$. aureus (gram-positive, TISTR 1466) using disc diffusion method. $S$. aureus was cultured in tryptone soy broth. Melted nutrient agar was transferred to Petri dishes and allowed to solidify. The bacteria strain suspension was transferred and allowed to spread uniformly to plates over agar surface. The film $\left(0.5 \mathrm{~cm}^{2}\right)$ was placed on the nutrient agar plate seeded with $10^{8} \mathrm{CFU} \mathrm{ml}{ }^{-1}$ of bacteria culture $(0.1 \mathrm{ml})$. The inhibition zone was measured after $24 \mathrm{~h}$ incubation at $37^{\circ} \mathrm{C}[1]$.

\section{Result and discussion}

Figure 1 represents the FTIR spectra of $\mathrm{C}, \mathrm{C}-\mathrm{ZnO} 0.5$ and $\mathrm{C}$ ZnO1.0. FTIR specturm of chitosan shows the basic characteristic peaks at $2853\left(-\mathrm{CH}_{2-}\right.$ asymmetric stretching $), 1744 \quad(\mathrm{C}=\mathrm{O}$ stretching), 1541 (- $\mathrm{NH}_{2}$ streching) 1465 (C-N stretching) and 1161 $\mathrm{cm}^{-1}$ (asymmetric stretching of -C-O-C- linkage) [2, 6, 11]. Pure chitosan exhibited a band at $3340 \mathrm{~cm}^{1}$ (-OH strectch) while C$\mathrm{ZnO0.5}$ and $\mathrm{C}-\mathrm{ZnO} 1.0$ films exhibit thinner band at $3351 \mathrm{~cm}^{-1}$ which can be indexed to the strecthing vibrations of pendant groups such as $-\mathrm{NH}_{2}$ and $-\mathrm{OH}$ on the chitosan matrix [11, 13]. Two strong peaks observed at 1744 and $1640 \mathrm{~cm}^{-1}$ of C-ZnO films were due to the formation of crosslink between chitosan and $\mathrm{ZnO}$ [8]. Besides that, the $\mathrm{C}-\mathrm{ZnO0.5}$ and $\mathrm{C}-\mathrm{ZnO} 1.0$ spectra exhibit sharper peaks at 1150,1058 and $1033 \mathrm{~cm}^{-1}$ which represented the skeletal vibration involving asymmetric stretching of -C-O-Cbridge compared to the band at $1161 \mathrm{~cm}^{-1}$ in IR spectra of chitosan film [13]. As shown in Table 1, noticeably shift in the position of of bands towards lower and higher wave number region in the IR spectra of $\mathrm{C}-\mathrm{ZnO} 0.5$ and $\mathrm{C}-\mathrm{ZnO} 1.0$ indicates stronger interaction between functional groups and $\mathrm{ZnO}$ particles rather than chitosan alone. The decrease in intensity of the absorption bands at C$\mathrm{ZnO0.5}$ and $\mathrm{C}-\mathrm{ZnO} 1.0$ spectra can be associated that the amino groups of chitosan stretching vibrations increased and overlapped with carboxyl group of zinc oxide through electrostatic interaction [2].

Table 1: Shift of major peaks in FTIR spectra of C-ZnO films.

\begin{tabular}{|c|c|c|}
\hline $\begin{array}{c}\text { Major } \\
\text { function group }\end{array}$ & $\begin{array}{c}\text { Wave number } \\
\text { observed in pure } \\
\text { chitosan film, } \mathrm{C}\left(\mathrm{cm}^{-1}\right) \\
\end{array}$ & $\begin{array}{l}\text { Wave number observed in } \\
\text { composite film, C- } \mathrm{ZnO0.5} \\
\text { \& C-ZnO1.0 }\left(\mathrm{cm}^{-1}\right)\end{array}$ \\
\hline$-\mathrm{OH}$ & 3340 & 3351 \\
\hline$-\mathrm{CH}_{2^{-}}$ & $2923 \& 2853$ & $2923 \& 2853$ \\
\hline $\mathrm{C}=\mathrm{O}$ & 1744 & $1744 \& 1640$ \\
\hline$-\mathrm{NH}_{2}$ & 1541 & 1578 \\
\hline $\mathrm{C}-\mathrm{N}$ & 1465 & 1378 \\
\hline -C-O-C- & 1161 & $1150,1058 \& 1033$ \\
\hline $\begin{array}{c}\text { Spectrum } \\
101 \\
100 \\
98 \\
96 \\
94 \\
94 \\
92 \\
589 \\
88 \\
86 \\
84\end{array}$ & $\begin{array}{l}2853 \\
2923\end{array}$ & ${ }_{1058}^{1150} 1033$ \\
\hline $\begin{array}{ll}82 \\
4000\end{array}$ & $2500 \mathrm{~cm}-1{ }^{2000}$ & $\begin{array}{ll}1500 & 1000\end{array}$ \\
\hline
\end{tabular}

Fig. 1: The IR spectra of $\mathrm{C}, \mathrm{C}-\mathrm{ZnO} 0.5$ and $\mathrm{C}-\mathrm{ZnO1} .0$.

The water vapour transmission rates of $\mathrm{C}-\mathrm{ZnO}$ films are displayed in Table 2. Water vapor transmission rate of film is much important since one of the main functions of film is to hinder moisture transfer between packaged food and surrounding atmosphere [13]. As compared to pure chitosan, both films, C-Zn0.5 and CZn1.0 exhibited lower WVTR values of $20.60 \mathrm{~g} / \mathrm{h} \mathrm{m}^{2}$ and 19.37 $\mathrm{g} / \mathrm{h} \mathrm{m}{ }^{2}$ respectively. Result also revealed that the increase in $\mathrm{ZnO}$ amount subsequently decreased the WVTR, which is attributed to the cross-linked zinc ions rendered the network denser in the film [13]. According to study from Rahman et.al., the incorporation of zinc oxide reduced the segmental motion and porosity in the polymer surface of chitosan leading to low water vapour transmission [11]. The covalent bonding of zinc oxide onto chitosan may obstructed the inter- and intra- molecular hydrogen bond network of chitosan, which greatly limited the availability of hydrophilic domain of chitosan and thus decreased the affinity of films toward water [3, 14]. After all, the obtained values are still high for dry food and pharmaceuticals [15]. 
Table 2: Water vapour tranmission rate of films.

\begin{tabular}{|c|c|}
\hline Sample & $\begin{array}{c}\text { Water Vapour Transmission Rate, } \\
\text { WVTR }\left(\mathrm{g} / \mathrm{h} \mathrm{m}^{2}\right)\end{array}$ \\
\hline C (control) & $21.02 \pm 0.32$ \\
\hline C-ZnO0.5 & $20.60 \pm 0.17$ \\
\hline C-ZnO1.0 & $19.37 \pm 0.11$ \\
\hline
\end{tabular}

*Each value indicates mean of three set of samples. \pm Standard deviation.

The contact angle value (Figure 2) in $\mathrm{C}-\mathrm{ZnO} 1.0$ film increased by $30.5 \%$ when compared to chitosan film due to change in hydrophobicity of film by the presence of zinc oxide content. Previous studies show that $\mathrm{C}-\mathrm{ZnO}$ film results in higher contact angle value than chitosan alone because $\mathrm{ZnO}$ ensure an affinity to avoid the spreading of the water drop over the film surface resulting in an increase of the surface hydrophobicity $[1,16]$.

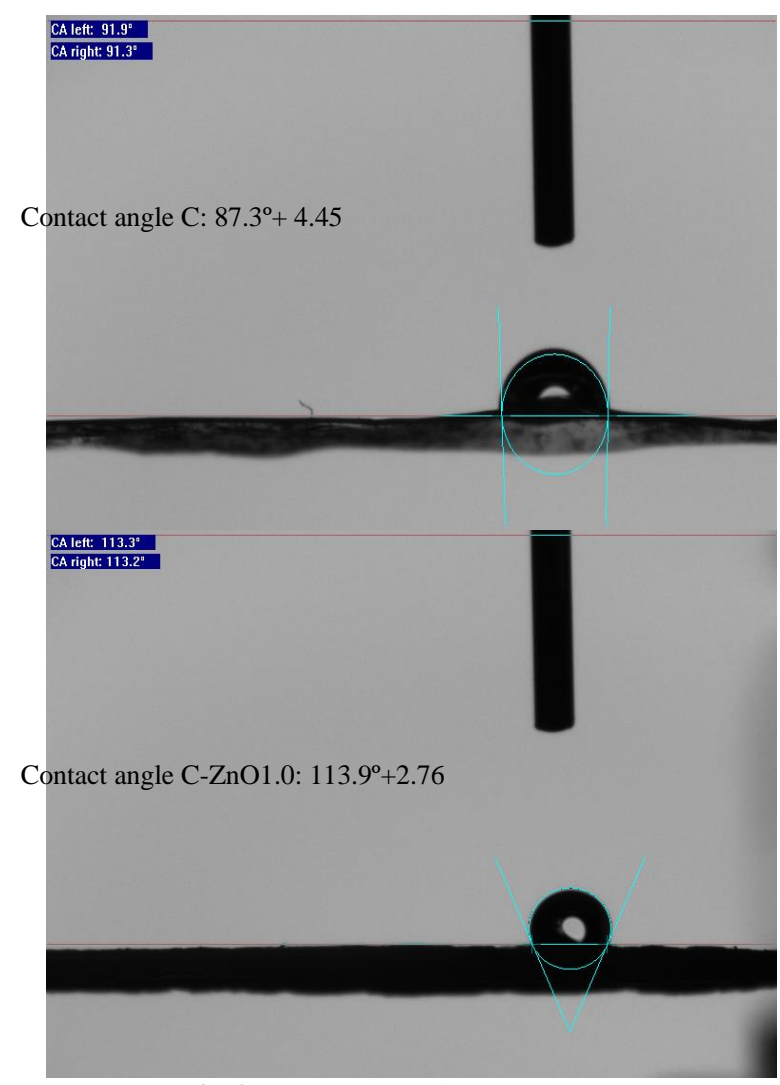

Fig. 2: Contact angle of $\mathrm{C}$ and $\mathrm{C}-\mathrm{ZnO} 1.0$

Mechanical properties for films for different zinc oxide loading is presented in Table 3. Chitosan film exhibited tensile strength and elongation at break values of $2.437 \pm 0.67 \mathrm{MPa}$ and $3.07 \pm 0.04 \%$ respectively. The tensile strength and elongation of chitosan-zinc oxide films were quite different. $\mathrm{C}-\mathrm{ZnO} 0.5$ and $\mathrm{C}-\mathrm{ZnO} 1.0$ films showed 1.5 times and 2.5 times higher in tensile strength respectively while increase $40 \%$ and $70 \%$ in elongation compared to chitosan films. It can be seen that the increase in the tensile strength and the elongation at break of the chitosan upon the incorporation of the zinc oxide leading to a tougher film compared to the bare chitosan film [16]. The increase in tensile strength could be attributed to the good dispersion of zinc oxide and intermolecular cross linking effect generated between chitosan and zinc oxide $[11,13,16]$.

Table 3: Tensile strength and elongation of $\mathrm{C}, \mathrm{C}-\mathrm{ZnO} 0.5$ and $\mathrm{C}-\mathrm{ZnO} 1.0$ films.

\begin{tabular}{|c|c|c|}
\hline Samples & Tensile strength (MPa) & Elongation (\%) \\
\hline $\mathrm{C}$ (control) & $2.437 \pm 0.67$ & $3.07 \pm 0.04$ \\
\hline $\mathrm{C}-\mathrm{ZnO} 0.5$ & $3.712 \pm 1.65$ & $4.67 \pm 0.04$ \\
\hline $\mathrm{C}-\mathrm{ZnO} 1.0$ & $6.058 \pm 0.16$ & $5.22 \pm 0.02$ \\
\hline
\end{tabular}

*Each value indicates mean of three set of samples, elongation \pm standard deviation.

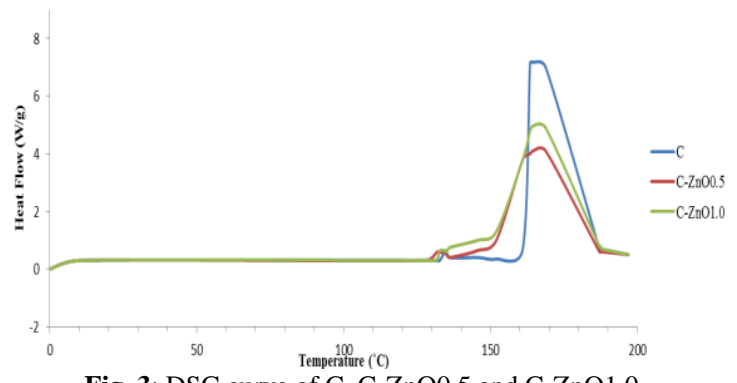

Fig. 3: DSC curve of $\mathrm{C}, \mathrm{C}-\mathrm{ZnO} 0.5$ and $\mathrm{C}-\mathrm{ZnO} 1.0$.

Figure 3 displays the DSC curves of C, C-ZnO0.5 and C-ZnO1.0. The studies on thermal stability and glass transition temperature, $\mathrm{T}_{\mathrm{g}}$ values of any polymer have vital importance in packaging. As seen from the curves, all films exhibited the same thermal trend with one significant endothermic peak. A single glass transition temperature indicates that chitosan and zinc oxide have good miscibility and form a wide range of blends due to the interaction produced by hydrogen bonds and electrostatic interactions [2]. The exothermic peak which represented the dehydration temperature was absence in the curve. The absence of exothermic peak suggests that all bound water was completely removed from the samples after drying [16]. The thermal stability of film is lifted if there is a shift of glass transition temperature in composite film [2]. However, the insignificant changes in $\mathrm{T}_{\mathrm{g}}$ could be due to the incorporation of zinc oxide that did not affect the thermal stability of the film.

Table 4: Inhibition zone of $\mathrm{C}, \mathrm{C}-\mathrm{ZnO} 0.5$ and $\mathrm{C}-\mathrm{ZnO} 1.0$ against S. aureus.

\begin{tabular}{|c|c|}
\hline Samples & Inhibition zone $(\mathrm{mm})$ \\
\hline $\mathrm{C}$ (control) & - \\
\hline $\mathrm{C}-\mathrm{ZnO0} .5$ & $5.10 \pm 0.04$ \\
\hline $\mathrm{C}-\mathrm{ZnO} 1.0$ & $7.50 \pm 0.02$ \\
\hline
\end{tabular}

*Each value indicates mean of three set of readings, inhibition zone \pm standard deviation

The antimicrobial effects against $S$. aureus of chitosan and chitosan-zinc oxide films after $24 \mathrm{~h}$ contact time are shown in Figure 4 and listed in Table 4. The inhibition ring of C-ZnO1.0 film was $47 \%$ larger than C-ZnO0.5 film. Results indicated that the inhibitory zone of $\mathrm{C}-\mathrm{Zn}$ films increases with increasing of zinc oxide loading. Both C-ZnO films exhibited good inhibiting ability on $S$. aureus while chitosan alone did not show any inhibition zone. The antimicrobial activity of composite film directly correlates with surface area and concentration of $\mathrm{ZnO}[7,17]$. It is anticipated that when the $\mathrm{ZnO}$ was incorporated, it can penetrate into microorganism membranes due to their large interfacial area, thus enhancing their antimicrobial efficiency [11]. Moreover, the enhanced antimicrobial activity can be attributed to surface defects on $\mathrm{ZnO}$ abrasive surface texture [12].

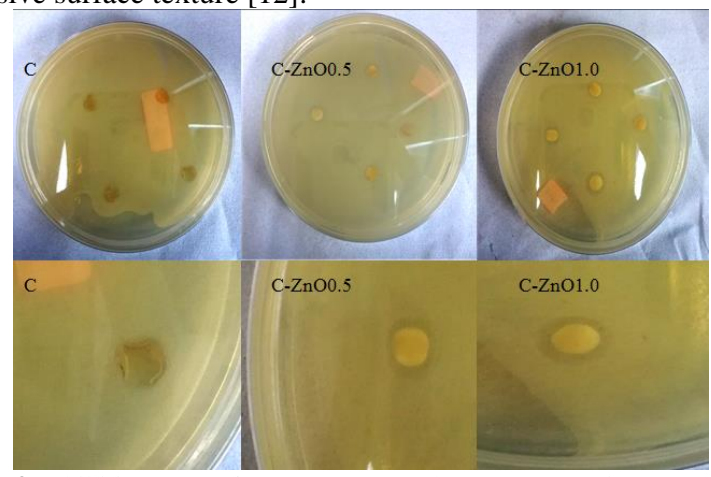

Fig. 4: Inhibition zone of $\mathrm{C}, \mathrm{C}-\mathrm{ZnO} 0.5$ and $\mathrm{C}-\mathrm{ZnO} 1.0$ against $\mathrm{S}$. aureus

\section{Conclusion}

$\mathrm{C}-\mathrm{ZnO}$ films were prepared and characterized in this study. The chemical structure of $\mathrm{C}-\mathrm{ZnO}$ film has exhibited improved proper- 
ties attributed to possible interaction between chitosan and zinc oxide. The improved mechanical property was evidenced via enhancement of tensile strength in the presence of $\mathrm{ZnO}$. The barrier properties of films using WVTR and contact angle were also improved with the addition of $\mathrm{ZnO}$. C-ZnO1.0 exhibits the highest inhibition efficiency in antimicrobial activity. Moreover, these properties were linearly related to the amount of $\mathrm{ZnO}$ incorporated. The antimicrobial results with enhanced mechanical and barrier properties demonstrated that $\mathrm{C}-\mathrm{ZnO}$ film could be suggested as potential active food packaging material.

\section{Acknowledgement}

The authors gratefully acknowledge Ministry of Higher Education of Malaysia for the research project financial support under transdisciplinary research grant scheme (TRGS) vot No. T 002. In addition, Ernna Erynna Mohamad Kahar was also acknowledged for her technical help.

\section{References}

[1] Youssef AM, El-Sayed SM, El-Sayed HS, Salama HH \& Dufresne A, "Enhancement of Egyptian soft white cheese shelf life using a novel chitosan/carboxymethyl cellulose/zinc oxide bionanocomposite film", Carbohydrate Polymers, Vol. 151, pp. 9 19, 2016.

[2] Qiao C, Ma X, Zhang J \& Yao J, "Molecular interactions in gelatin/ chitosan composite films", Food Chemistry, Vol. 235, pp. 45-50, 2017.

[3] Karpuraranjith M \& Thambidurai S, "Chitosan/zinc oxidepolyvinylpyrrolidone (CS/ZnO-PVP) nanocomposite for better thermal and antibacterial activity", International Journal of Biological Macromolecules, Vol. 2, (2017), pp. 112-130.

[4] Sanuja S, Agalya A \& Umapathy MJ, "Synthesis and characterization of zinc oxide-neem oil-chitosan bionanocomposite for food packaging application", International Journal of Biological Macromolecules, Vol. 74, (2015), pp. 76-84.

[5] Al-Naamani L, Dobretsov S \& Dutta J, "Chitosan-zinc oxide nanoparticle composite coating for active food packaging applications", Innovative Food Science and Emerging Technologies, Vol 38, (2016), pp. 231-237.

[6] Rahman PM, Abdul MVM \& Muraleedharan K, "Flexible chitosannano $\mathrm{ZnO}$ antimicrobial pouches as a new material for extending the shelf life of raw meat", International Journal of Biological Macromolecules, Vol. 97, (2017), pp. 382-391.

[7] Wang Y, Zhang Q, Zhang CC \& Li P, "Characterisation and cooperative antimicrobial properties of chitosan/nano-ZnO composite nanofibrous membranes", Food Chemistry, Vol. 132, (2012), pp. 419-427.

[8] Rahman PM, Abdul Mujeeb VM, Muraleedharan K \& Thomas SK "Chitosan/nano $\mathrm{ZnO}$ composite films: Enhanced mechanical, antimicrobial and dielectric properties", Arabian Journal of Chemistry, Vol. 106, (2016), pp. 301-309.

[9] Noshirvania N, Ghanbarzadeha B, Mokarrama RR \& Hashemib M "Novel active packaging based on carboxymethyl cellulosechitosan -ZnO NPs nanocomposite for increasing the shelf life of bread", Food Packaging and Shelf Life, Vol. 11, (2017), pp. 106114.

[10] Jebel SF \& Almasi H, "Morphological, physical, antimicrobial and release properties of $\mathrm{ZnO}$ nanoparticles-loaded bacterial cellulose films", Carbohydrate Polymers, Vol. 149, (2016), pp. 8-19.

[11] Rahman PM, Abdul Mujeeb VM, Muraleedharan K \& Thomas SK "Chitosan/nano $\mathrm{ZnO}$ composite films: Enhanced mechanical, antimicrobial and dielectric properties", Arabian Journal of Chemistry, Vol. 106, (2016), pp. 301-309.

[12] Rahman PM, Abdul Mujeeb VM \& Muraleedharan K, "Flexible chitosan-nano $\mathrm{ZnO}$ antimicrobial pouches as a new material for extending the shelf life of raw meat", International Journal of Biological Macromolecules, Vol. 97, (2017), pp. 382-391.

[13] Liu S, Yao F, Oderinde O, Li K, Wang H \& Zhang Z, "Zinc ions enhanced nacre-like chitosan/graphene oxide composite film with superior mechanical and shape memory proper-ties", Chemical Engineering Journal, Vol. 321, (2017), pp. 502-509.
[14] Siripatrawan U \& Vitchayakitti W, "Improving functional properties of chitosan films as active food packaging by incorporating with propolis," Food Hydrocolloids, Vol. 61, (2016), pp. 695-702.

[15] Hirvikorpia T, Vähä-Nissia M, Harlina A, Salomäkib M, Arevac S, Korhonend JT \& Karppinene M, "Enhanced Water Vapor Barrier Properties for Biopolymer Films by Polyelectrolyte Multilayer and Atomic Layer Deposited Al2O3 double-coating", Applied Surface Science, Vol 257, (2011), pp 9451-9454.

[16] J. Ahmed, M. Mehrajfatema, Y.A. Arfat, \& L. A. Thai, "Mechanical, thermal, structural and barrier properties of crab shell chitosan/graphene oxide composite films," Food Hydrocolloids, vol. 71, pp. 141-148., 2017.

[17] Noshirvania N, Ghanbarzadeha B, Mokarrama RR \& Hashemib M, "Novel active packaging based on carboxymethyl cellulosechitosan -ZnO NPs nanocomposite for increasing the shelf life of bread", Food Packaging and Shelf Life, Vol. 11, (2017), pp. 106114. 